\title{
EFFECT OF THE REGIONAL CLIMATE CHANGE ON RUNOFF FROM THE LAKE ONEGO WATERSHED \\ EFFECT OF THE REGIONAL CLIMATE CHANGE ON RUNOFF FROM THE LAKE ONEGO WATERSHED
}

\author{
L.E. Nazarova \\ Northern Water Problems Institute, Karelia, Russia \\ E-mail: nazarova@nwpi.krc.karelia.ru
}

\begin{abstract}
As a result of the statistical analysis of the meteorological and water balance data for Onego Lake watershed over the period 1950-2000, noticeable changes were detected. It was found that time series of annual air temperature, precipitation and evapotranspiration over 50-year period contains positive linear trends, but no change in total streamflow to the lake has so far followed. Potential changes in the regional climate and hydrological regime for the period 2000-2050 were estimated using the results of numerical modeling with the ECHAM4/OPYC3 model for two scenarios of the global climate change. The estimation of these data shows that a general tendency to increase of annual air temperature and precipitation will remain in the new climate Mean annual precipitation will increase about 30-50 mm, mean average annual air temperature for the next 50-years period will rise from 1.6 up to 2.7-3.0 ${ }^{\circ} \mathrm{C}$. Our estimation shows that for both scenarios all water balance parameters, excluding river runoff, will increase.
\end{abstract}

Keywords: climatic regime, regional changes, air temperature, precipitation, evapotranspiration, water balance parameters.

\section{Introduction}

According to observation data, the global climate system has been changing since the early $20^{\text {th }}$ century. Ideas about the basic mechanisms behind the changes differ - whether it is natural processes that dominate or human-induced ones. Climate data for Russian Karelia were summarized in the 1960s-1980s [2; 4; 7; 8]. Obviously, changes of the last 15-20 years remained unaccounted. And it is during this time that patterns of change appear most interesting in view of global climate warming. Close analysis of regional climatic distinctions, study of the response of natural systems to climate change through representative observations is a good way to address the challenges of climate change.

\section{Materials and methods}

Statistical analysis of the climatic regime in Lake Onego catchment area was based on 1950-2004 observation data from the Northwestern Hydrometeorology and Environmental Monitoring Authority's weather stations situated within the catchment area. Annual temperature and precipitation averages for Lake Onego catchment area were calculated using the Thiessen polygon method. Mean weighted annual runoff from three major river systems (rivers Shuja, Suna and Vodla) over the period 1946-2000 was estimated relying on hydrologic network data, and the relation of the resultant value with computed annual inflow to Lake Onego in the period 1960-1975 was found [3]. Calculations yielded multiple regression equations, which were then used to compute the series of annual inflow to Lake Onego over the period 1946-2000.

To estimate potential changes in principal characteristics of the climate in the study area, and to calculate temperature characteristics of Lake Onego and annual runoff from the catchment area we employed the results of numerical modeling using the atmosphere-ocean general circulation model ECHAM4/OPYC3 developed by the Max Planck Institute for Meteorology in Hamburg, Germany [1]. Calculations were made for two climate change scenarios. The assumption for the first one (named scenario $\mathrm{G}$ in the paper) is that the content of $\mathrm{CO}_{2}$ and other greenhouse gases in 
the Earth's atmosphere will double between 2000 and 2100, and the second one (GA scenario) additionally envisages a rise in the concentration of technogenic aerosols. To check agreement between observed data from weather stations and modeled data on monthly and annual precipitation and air temperature, we selected most closely located "weather station - grid node" pairs and compared instrumental and computed data. Also, annual air temperature and precipitation averages for the study area based on factual and modeled data were studied. The time period from 1960 to 1999 was chosen as the control. Analysis of measured and modeled data for some stations showed good agreement for mean monthly air temperatures, but correlation for total monthly precipitation was unsatisfactory, the difference between modeled and measured values deviating far from zero rather often. The problem of adequacy and accuracy of Karelia's temperature and precipitation regime modeling by ECHAM-4 is considered in detail in papers by Yu. Salo [5; 6].

\section{Results and discussion}

Regional changes in surface air temperature in the study area generally reflect the positive global temperature trend over the $20^{\text {th }}$ century. The overall trend of surface air temperature in Karelia on average is $+0.2^{\circ} \mathrm{C}$ over 100 years $(1901-2000)$ and $+0.6^{\circ} \mathrm{C}$ over 50 years (1951-2000). The trend in Lake Onego catchment is $+0.9^{\circ} \mathrm{C}$ over 50 years. Analysis of changes in air temperature by months in 1951-2000 has shown that a positive linear trend of mean monthly temperature that would be significant at a Student's t-test 95\% confidence level occurs only in March, and amounts to 3.5 to $5.1^{\circ} \mathrm{C}$ over 50 years in different localities within the catchment area. Warming tendencies are observed in Karelia from January to June. In the same years, temperature changes in summer and most of autumn have different directions and low absolute values (less than $1.5^{\circ} \mathrm{C} / 50 \mathrm{yrs}$.). By November, the tendency changes for cooling by $0.6-1.3^{\circ} \mathrm{C} / 50 \mathrm{yrs}$. throughout Lake Onego catchment.

A manifestation of change in the temperature regime in the study area is prolongation of the icefree period on Lake Onego. Judging by the dates of freeze-up beginning and break-up on Lake Onego in the period from 1884 to 1998 , the number of days when the lake was free of the ice cover increased by the late $20^{\text {th }}$ century from 217 to 225 on average. Duration of the ice-free period on Lake Onego increased because ice break-up in spring shifted by 8 days towards earlier time.

Analysis of changes in precipitation volumes in the study area over the second half of the $20^{\text {th }}$ century has demonstrated that although linear trends of total monthly precipitation have different directions during a year, total annual precipitation in Lake Onego catchment area has increased over the stated period (by $45 \mathrm{~mm} / 50$ yrs. on average). An upward trend in precipitation volumes is observed at all stations from October through June. Trends from July through September have different directions.

Since Lake Onego is, in fact, a storage reservoir, we chose to study water supply to the lake as a climate-dependent element. To estimate the effect of climate change on streamflow from the catchment area we found the relationship between streamflow and climatic characteristics. The water budget equation for annual intervals may take the form:

where $\mathrm{P}$ is total precipitation, $\mathrm{mm}$;

$$
\mathrm{P}-\mathrm{R}-\mathrm{E}\left[\mathrm{P}, \mathrm{E}_{\mathrm{o}}(\mathrm{T})\right] \pm \mathrm{W}=0
$$

$\mathrm{R}$ - total streamflow, mm;

$\mathrm{E}$ - total evaporation from the catchment area;

$\mathrm{E}_{\mathrm{o}}$ - evaporability, mm;

$\mathrm{W}$ - remainder term combining accumulated and unaccounted components of the annual budget, as well as estimation errors of all characteristics.

Total evaporation from river watersheds was calculated using E. Olderkop's formula:

$$
\mathrm{E}=\mathrm{E}_{\mathrm{o}} \cdot \tanh \left(\mathrm{P} / \mathrm{E}_{\mathrm{o}}\right)
$$

where evaporability $\mathrm{E}_{\mathrm{o}}$ was calculated to the formula developed for Karelia by Yu. Salo [5]: 


$$
\mathrm{E}_{\mathrm{o}}=239+62 \mathrm{~T}+2,14 \mathrm{~T}^{2}
$$

Then we found the dependence of $\mathrm{W}$ on catchment-averaged annual air temperature and total annual precipitation; pair-wise correlation coefficients were -0.81 and +0.59 , respectively:

$$
\mathrm{W}=-211+0,38 \mathrm{P}-46,04 \mathrm{~T}
$$

The coefficient of multiple correlations for the resultant relationship equals 0.80 , the estimation error is $5.7 \%$. The formula gained for Lake Onego catchment can be applied to calculate the parameter $\mathrm{W}$ using series of annual air temperature and total annual precipitation.

Fig. 1 shows the values of total inflow to Lake Onego based on 1951-2000 observations, and estimates of total inflow to the lake based on the formulae above. It is clear from the graphs that the computed results agree well with measured values. Correlation coefficient is 0.83 , mean estimation error is $10 \%$. The above computation scheme was then used to process model data.

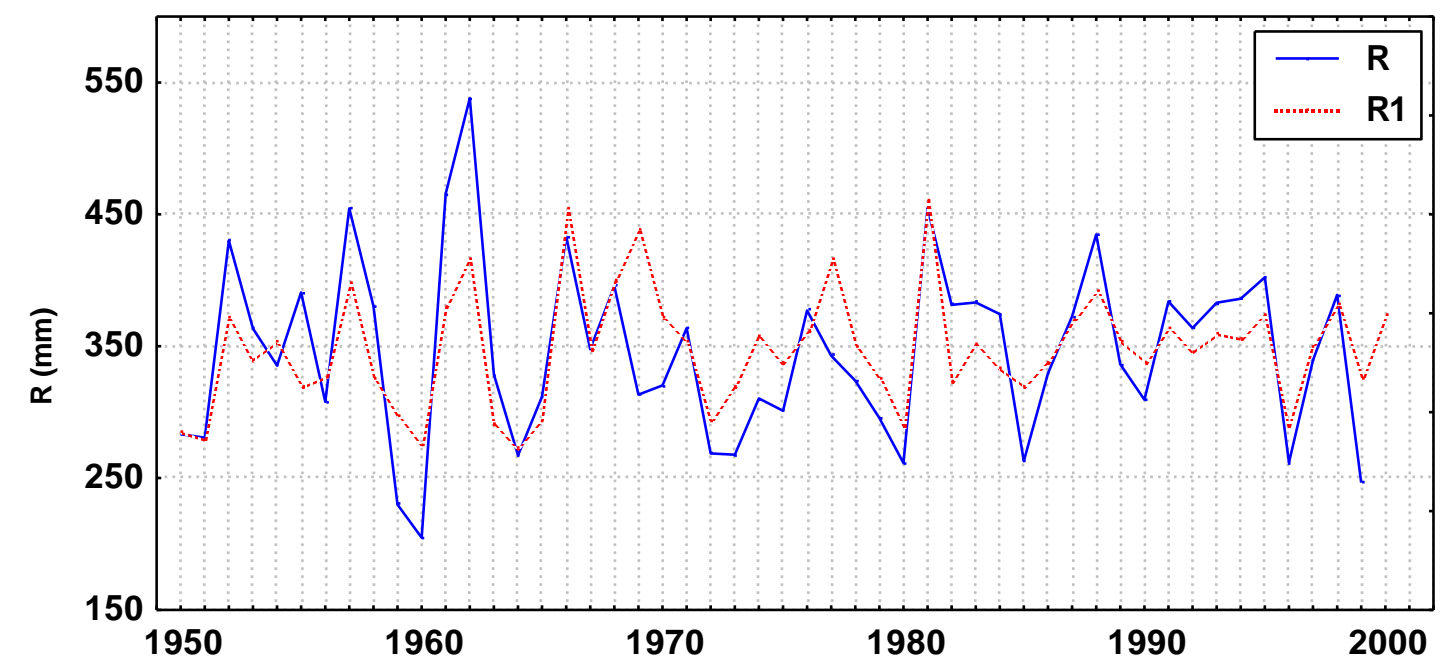

\section{Fig. 1. Total inflow to Lake Onego: observed data from 1951-2000 (R) and calculation results of equations (1-4) (R1)}

One should note that due to high among-year variability of total streamflow to Lake Onego, there are no positive or negative trends in the series of measured values of this parameter over the 50year period of 1951-2000.

The next step was to quantify potential changes in climate characteristics in Lake Onego area and annual runoff from the catchment for the period up to 2050, if climate change scenarios (ECHAM4/ OPYC3) come true. The following conclusions were drawn from the analysis of the modeled data.

Air temperature in Lake Onego catchment may rise by $0.5-1.7{ }^{\circ} \mathrm{C}$ in the period $2001-2050$. Normal annual total evaporation may increase by values of $20 \mathrm{~mm}$ (GA scenario) to $80 \mathrm{~mm}$ (G scenario). Two alternative scenarios are possible for changes in total annual precipitation. Scenario $\mathrm{G}$ envisages an increase in annual precipitation by $40 \mathrm{~mm}$, and scenario GA predicts a decrease in precipitation by ca. $10 \mathrm{~mm}$. This would result in very minor change (within measurement (calculation) accuracy limits) in the volume of inflow to Lake Onego (Tab. 1).

In addition to the "greenhouse" scenarios of the ECHAM-4 model, hypothetical scenarios of change in air temperature and precipitation (air temperature rise or fall by $1-2{ }^{\circ} \mathrm{C}$ at an increase or decrease in precipitation by $10-20 \%$ ) were employed to assess the impact of climate change on streamflow to Lake Onego. The results of the calculations are shown in Fig. 2. 
Table 1.

Potential changes in multiannual means of air temperature and water budget components in Lake Onego catchment area

\begin{tabular}{|l|l|c|c|}
\hline \multicolumn{1}{|c|}{ Parameter } & \multicolumn{1}{|c|}{ Period } & \multicolumn{1}{|c|}{$\begin{array}{c}\text { Average for the } \\
\text { period }\end{array}$} & $\begin{array}{c}\text { Potential changes } \\
\text { compared with 1951- } \\
2000\end{array}$ \\
\hline Air temperature, ${ }^{\circ} \mathrm{C}$ & $1951-2000$ & $2.3 \pm 0.2^{*}$ & +1.7 \\
& $2001-2050$, scenario G & $4.0 \pm 0.3$ & +0.5 \\
& $2001-2050$, scenario GA & $2.8 \pm 0.3$ & +39 \\
\hline Precipitation, mm & $1951-2000$ & $744 \pm 25$ & -9 \\
& $2001-2050$, scenario G & $783 \pm 17$ & +82 \\
& $2001-2050$, scenario GA & $735 \pm 12$ & +19 \\
\hline Total evaporation, & $1951-2000$ & $434 \pm 13$ & +5 \\
mm & $2001-2050$, scenario G & $516 \pm 17$ & -11 \\
\hline Streamflow, mm & $2001-2050$, scenario GA & $453 \pm 9$ & \\
& $1951-2000$ & $346 \pm 14$ & $351 \pm 7$ \\
& $2001-2050$, scenario G & $335 \pm 7$ & \\
\hline
\end{tabular}

* - numbers after the sign « $₫ »$ denote estimation error.

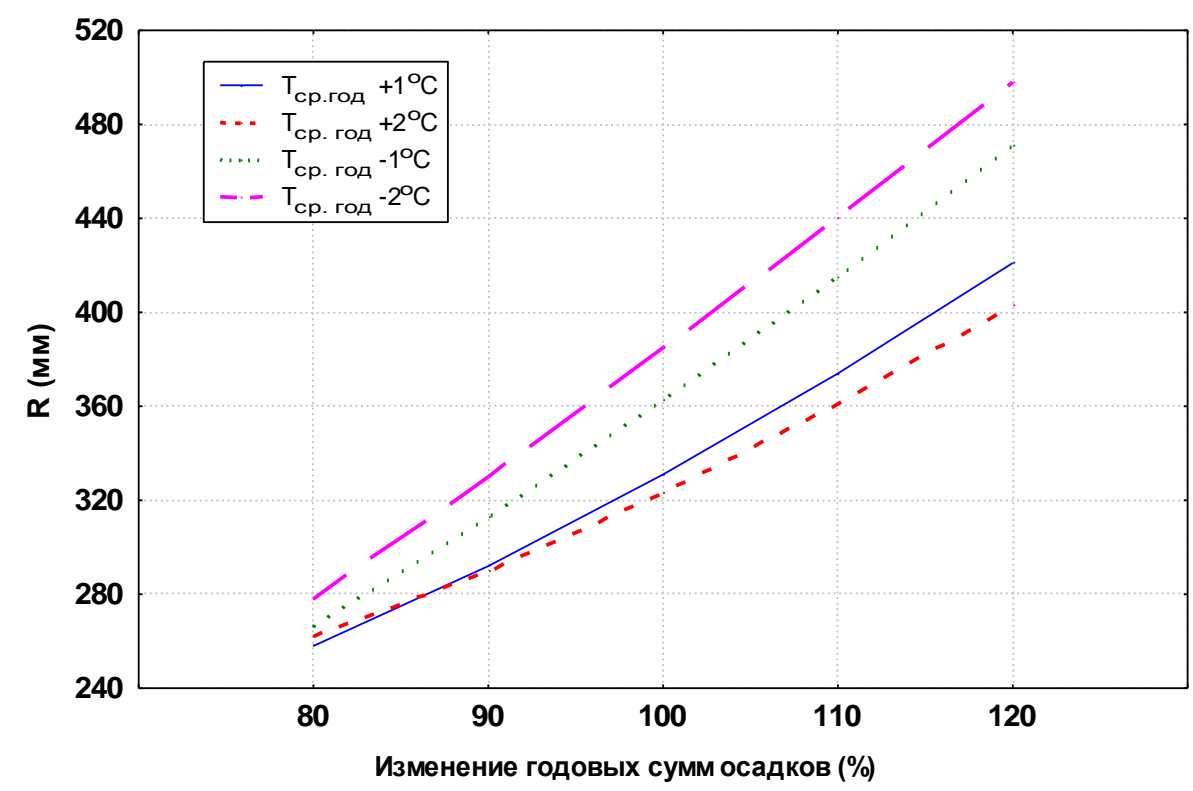

Fig. 2. Changes in inflow to the lake under different climate change scenarios

(100\% - amount of precipitation in the catchment area under current conditions)

1 - if mean annual air temperature rises by $1^{\circ} \mathrm{C} ; 2-$ if mean annual air temperature rises by $2^{\circ} \mathrm{C} ; 3-$ if mean annual air temperature falls by $1^{\circ} \mathrm{C} ; 4-$ if mean annual air temperature falls by $2^{\circ} \mathrm{C}$.

If air temperature rises by $1{ }^{\circ} \mathrm{C}$, total inflow to Lake Onego may remain the same, given that total annual precipitation increases by ca. $3 \%$, and if warming reaches $2^{\circ} \mathrm{C}-$ by ca. $6 \%$. If mean annual air temperature in the catchment falls by $1^{\circ} \mathrm{C}$, streamflow to the lake would not change, given that total annual precipitation decreases by ca. $3 \%$, and if cooling is $2{ }^{\circ} \mathrm{C}-$ by ca. $7 \%$.

\section{Conclusions}

Having analysed the data obtained we found annual air temperature and total annual precipitation to have increased in Lake Onego catchment over the second half of the $20^{\text {th }}$ century, so far without leading to changes in total streamflow to the lake. The patterns identified in the change of major characteristics of the region's climate and the results on potential changes in the hydrological regime of Lake Onego catchment area can be taken into account when planning 
water management projects to ensure sustainable use and conservation of this aquatic system, which is unique in terms of potable water supply, transport, energy production and recreation.

\section{References}

1. Bengtsson L. Numerical modeling of the Earth's Climate. Publ. of Max-Planck Inst. of Meteorology, Hamburg, 1997. $94 \mathrm{p}$.

2. Filatov N.N. Climate Change in East Fennoscandia. Petrozavodsk: Karelian Research Centre of RAS, 1997. 147 p.

3. Karpechko V.A., Salo Yu.A. Water Resources // Lake Onego. Environmental Problems. Petrozavodsk, 1999. pp.15-22.

4. Romanov A.A. On the Climate of Karelia. Petrozavodsk, 1961. 139 p.

5. Salo Yu.A. Patterns in among-year variations of water budget components in Karelia. PhD thesis summary. St. Petersburg, 2003. $24 \mathrm{p}$.

6. Salo Yu.A., Nazarova L.E. Potential changes in the climate and water budget components in Karelia in 20012050 // Climate of Karelia: Variability and Effect on Water Bodies and Watersheds. N.N. Filatov, ed.-in-chief. Petrozavodsk: Karelian Research Centre of RAS, 2004. pp. 88-101.

7. Shver Ts.A. and L.S. Rakova, eds. Climate of Sortavala. Leningrad, 1988. 117 p.

8. Shver Ts.A., ed. Climate of Petrozavodsk. Leningrad, 1982. 212 p. 